\title{
Assertion: The Constitutive Rule Account and the Engagement Condition Objection
}

\author{
Felix Bräuer ${ }^{1}$ (D)
}

Received: 18 January 2021 / Accepted: 18 August 2021

(C) The Author(s) 2021

\begin{abstract}
Many philosophers, following Williamson (The Philosophical Review 105(4): 489-523, 1996), Williamson (Knowledge and its Limits, Oxford, Oxford University Press, 2000), subscribe to the constitutive rule account of assertion (CRAA). They hold that the activity of asserting is constituted by a single constitutive rule of assertion. However, in recent work, Maitra (in: Brown \& Cappelen (ed). Assertion: new philosophical essays, Oxford, Oxford University Press, 2011), Johnson (Acta Analytica 33(1): 51-67, 2018), and Kelp and Simion (Synthese 197(1): 125-137, 2020a), Kelp and Simion (in: Goldberg (ed) The Oxford Handbook of Assertion, Oxford, Oxford University Press, 2020b) aim to show that, for all the most popular versions of the constitutive rule of assertion proposed in the literature, asserting is not an activity constituted by a single constitutive rule and that therefore CRAA is very likely false. To reach this conclusion, they all present a version of what can be dubbed the engagement condition objection. That is, they each propose a necessary condition on engaging in rule-constituted activities. Then they argue that, for all the most popular versions of the constitutive rule of assertion proposed in the literature, one can make assertions without satisfying this condition. In response, I present a counterexample that shows that the proposed engagement conditions lead to counterintuitive results, and I propose an alternative that better captures our intuitions. Then I argue that this alternative engagement condition is compatible with all the most popular versions of the constitutive rule of assertion.
\end{abstract}

\section{Introduction}

According to the constitutive rule account of assertion (CRAA), proposed by Timothy Williamson $(1996,2000)$, the activity of asserting is constituted by a single constitutive rule, much like the activity of playing a game is constituted by its rules

Felix Bräuer

felix.braeuer@phil.uni-mannheim.de

1 Department of Philosophy, Lehrstuhl Philosophie I, University of Mannheim, L 9, 5 - Raum 007, 68161 Mannheim, Germany 
(cf. Williamson, 2000: 238). The rules of chess, for example, constitute the activity of playing chess in so far as these rules (when in force ${ }^{1}$ ) govern the antecedently existing activity of moving differently shaped pieces on the board and thereby make it possible to perform the new activity of playing chess. Put differently, without the constitutive rules of chess, one can move pieces on the board, but one can't, in virtue of doing so, play chess (cf. Reiland, 2020:143). ${ }^{2}$ Moreover, in so far as these rules are unique to playing chess, they make playing chess the activity that it is and thereby differentiate it from other game-playing activities with other rules, like playing draughts or halma (cf. e.g. Reddiford, 1985: 42; Williamson, 2000: 241). Analogously, a rule of assertion is supposed to constitute the activity of asserting in so far as this rule (when in force) governs the antecedently existing activity of saying that $p$ and thereby makes it possible to perform the new activity of asserting that $p$. Put differently, without the constitutive rule of assertion, one can say that $p$, but one can't, in virtue of doing so, assert that $p$ (cf. Reiland, 2020: 143). Moreover, in so far as this rule is supposed to be unique to asserting, it shall make asserting the activity that it is and thereby differentiate it from other speech-activities with other rules, like ordering or promising (cf. e.g. Turri, 2014: 558; Johnson, 2018: 54 f.).

In its most general form, the proposed constitutive rule of assertion ( $C$ Rule) can be stated as follows:

$C$ Rule: $\forall a$ ( $a$ may say that $p$ iff $\mathrm{C} p)^{3}$

Different versions of $C$ Rule identify $\mathrm{C}$ with different properties. Arguably, the most popular versions of $C$ Rule in the current literature are ${ }^{4}$ :

$K$ Rule: $\forall a$ ( $a$ may say that $p$ iff $a$ knows that $p$ ) (e.g., DeRose, 2002; Hawthorne, 2004; Williamson, 1996, 2000)

\footnotetext{
${ }^{1}$ What does it mean for constitutive rules to be in force? According to a plausible answer, due to Reiland (2020: 149), "constitutive rules like the rules of games are in force for us on an occasion if we decide that they're in force for us on that occasion". For games one plays with oneself, such as solitaire, this means privately "committing" to their constitutive rules. For games that one plays with others, such as chess, this means that "one has to publicly signal one's acceptance of the rules to the other players" (cf. Reiland, 2020: 150; for related discussion see Ridge 2019, 2020).

${ }^{2}$ Constitutive rules are often contrasted with regulative rules, such as the rules that regulate driving in traffic. Following the above characterization of constitutive rules, we can put the difference as follows. While constitutive rules govern an antecedently existing activity (like moving pieces on a board) and thereby make it possible to perform a new activity (like playing chess), regulative rules govern an antecedently existing activity (like making a left turn), but don't make it possible to perform a new activity (cf. Reiland, 2020: 142).

${ }^{3}$ The above formulation follows Reiland (2020) and is somewhat different from Williamson's (2000: 241) formulation of $C$ Rule: "One must: assert $p$ only if $p$ has C". The reason why I use the above formulation is that Williamson's formulation is potentially misleading. For $C$ Rule to constitute the activity of asserting, it has to govern the antecedently existing activity of saying that $p$, like the constitutive rules of chess govern the antecedently existing activity of moving one's pieces on the board. Hence, it is problematic to already talk of "assert[ing] $p$ " in the formulation of $C$ Rule (cf. Reiland, 2020: 143, fn. 12).

${ }^{4}$ Cf. Kelp \& Simion (2020a: 126). The following formulations are modelled on Reiland's (2020: 143) formulation of $K$ Rule, which he calls "(K-Assertion)". Also see the previous fn.
} 
$J$ Rule: $\forall$ a ( $a$ may say that $p$ iff $a$ is justified to believe that $p$ / $a$ justifiedly believes that $p$ ) (e.g., Douven, 2006; Hill \& Schechter, 2007; Kvanvig, 2011; Lackey, 2007, 2008) ${ }^{5}$

$B$ Rule: $\forall a$ ( $a$ may say that $p$ iff $a$ believes that $p$ ) (e.g., Bach, 2008; Hindriks, 2007)

T Rule: $\forall a$ ( $a$ may say that $p$ iff $p$ is true) (e.g., Weiner, 2005; Whiting, 2013)

Although CRAA has been embraced by many philosophers, it remains controversial. Since its proponents typically rely on the aforementioned analogy with the constitutive rules of a game to support CRAA, it is not surprising that a prominent line of objection against the latter consists in arguing that there are significant differences between the different versions of $C$ Rule and the constitutive rules of a game. In this paper, I focus on a version of this objection, recently presented by Ishani Maitra (2011), Casey Rebecca Johnson (2018), and Christoph Kelp \& Mona Simion (2020a; b), which can be dubbed the engagement condition objection (ECO). ${ }^{6}$ Roughly, they each propose a necessary condition on engaging in rule-constituted activities. Then they proport to show that, for all the versions of $C$ Rule just listed, one can make assertions without satisfying this condition and that therefore none of these versions of $C$ Rule is a viable candidate for being the single constitutive rule of assertion. From this they conclude that, very likely, CRAA is false. ${ }^{7}$

The aim of this paper is to defend CRAA against ECO. To do so, I will present a counterexample that shows that the conditions proposed by Maitra, Johnson, and Kelp \& Simion all lead to counterintuitive results and, drawing on Indrek Reiland (2020), propose a different condition that better captures our intuitions (\$3). Then, after responding to some objections (\$4), I will argue that this new condition doesn't pose a problem for CRAA ( $\$ 5)$. Finally, I wrap things up with a brief conclusion (§6). But first, let me lay out ECO in more detail.

\section{ECO}

In order to motivate her necessary condition on engaging in rule-constituted activities, Maitra (2011: 281) presents the following two cases:

(1) A batter, David, earns three strikes in a particular plate appearance. The umpire miscounts, and, instead of ruling that David is out, allows him a fourth strike.

\footnotetext{
5 While Douven and Lackey don't require that one actually believes $p$, Hill \& Schechter and Kvanvig do. Since this difference is irrelevant for the subsequent argumentation, I shall gloss over it in what follows.

${ }^{6}$ For somewhat different critiques of the game analogy, see Cappelen (2011) and Pagin (2016). For responses to Cappelen, see Goldberg (2015: ch. 1) and Kelp \& Simion (2020b). For a response to Pagin, see Kelp \& Simion (2020b).

7 Johnson (2018) and Kelp \& Simion (2020b) focus on K Rule. Maitra (2011) focuses on K Rule and T Rule. However, they point out that their critiques can be easily extended to other versions of $C$ Rule. Kelp \& Simion (2020a) explicitly discuss the different versions of $C$ Rule listed above.
} 
(To keep the case simple, assume that no one else present notices the mistake, and that the umpire is not usually prone to such mistakes).

(2) Another batter, Derek, has earned three strikes in a plate appearance. As is usual, the umpire has ruled that Derek is out. However, Derek refuses to leave the batter's box. He admits that he has already earned three strikes, but insists that the game would be more enjoyable for the spectators if he were allowed an extra strike.

And she observes that, intuitively, David still plays baseball, while Derek doesn't. Based on this intuition, she concludes that, in order to engage in a rule-constituted activity, one must not flagrantly violate one or more of its constitutive rules, where a rule violation is "flagrant" "if it is intentional and sufficiently marked" (cf. Maitra, 2011: 282). Maitra's engagement condition can be put as follows:

MEC: If an activity, $A$, is constituted by a set of constitutive rules, $R$, and if one flagrantly violates one or more members of $R$, then one doesn't engage in A. ${ }^{8}$

Like Maitra, Johnson (cf. 2018: 54) also gives a case-based motivation for her necessary engagement condition:

(3) A soccer player comes onto the field wielding a racquet.

And she observes that, intuitively, this soccer player doesn't play soccer. Based on this intuition, she concludes that, in order to engage in a rule-constituted activity, one must not violate one or more of its constitutive rules "with sufficient frequency, or with clear intent to do so" (cf. Johnson, 2018: 54). Johnson's engagement condition can be put as follows:

JEC: If an activity, $A$, is constituted by a set of constitutive rules, $R$, and if one violates one or more members of $R$ with sufficient frequency, or with the clear intent to do so, then one doesn't engage in $A$.

Kelp \& Simion (cf. 2020a: 129 f., 2020b: 65 f.) present the most detailed motivation for their necessary engagement condition, using the following cases:

(4) Your friend sits down with you to play a game of droughts but then constantly moves his pieces horizontally and vertically rather than diagonally.

(5) Your friend has promised you to bake Jamie Oliver's famous chocolate cake, but ultimately presents you with a mixture of kiwis, kidneys and marmite served in a martini glass.

\footnotetext{
${ }^{8}$ Here, and in what follows, the formulation is closely modelled on Kelp's \& Simion's formulation of their engagement condition, because I find their formulation especially clear.
} 
(6) Your friend sets out to play a game of tennis but then throws punches at his opponent until he has knocked him out.

(7) Your friend constantly responds to your questions by uttering only strings of the phoneme 'ka'.

(8) Your friend sits down to play Ace of Spades - a game that consists in turning over cards from a standard deck until one turns over the ace of spades. But then he regularly stops turning over cards when and only when he turns over the three of hearts. ${ }^{9}$

In each case they observe that, intuitively, this rather eccentric friend doesn't engage in the respective activity. He doesn't play droughts, bake a cake, play tennis, speak English, or play Ace of Spades. Based on this intuition, they conclude that, in order to engage in a rule-constituted activity, one must not violate too many of its constitutive rules too systematically (cf. Kelp \& Simion, 2020a: 129, 2020b: 66). Here is Kelp's \& Simion's engagement condition:

KSEC: If some activity $A$ is constituted by a set of constitutive rules, $R$, then one cannot violate too many members of $R$ too systematically without ceasing to engage in $A .{ }^{10}$

After introducing the proposed engagement conditions, ${ }^{11}$ let's look at what happens when they are applied to the different versions of $C$ Rule. A good place to start is a case presented by Maitra, concerning former baseball player Peter Rose. She writes: "In 2004, Rose admitted that he intentionally told a falsehood when he said several years earlier, "I'm not a chronic gambler" [...]. Even before Rose's 2004 admission, most baseball fans thought that his earlier utterance expressed a falsehood" (Maitra, 2011: 283). Now, plausibly, Rose violated $K$ Rule, J Rule, T Rule, and B Rule in a way that was both intentional and sufficiently marked. Still, intuitively, he asserted that he wasn't a chronic gambler (cf. Maitra, 2011: 283). Hence, given MEC or JEC, none of the rules just listed can be the single constitutive rule of assertion. A similar

\footnotetext{
9 For the sake of uniformity, case (8) has been slightly modified.

10 Moreover, to make their objection against CRAA more pointed, they formulate a second engagement condition for activities that are constituted by only a single constitutive rule: "If activity, $A$, is constituted by only a single constitutive rule, $r$, and if one violates $r$ with near maximum systematicity, then one does not engage in A" (Kelp \& Simion, 2020a: 130, also see Kelp \& Simion, 2020b: 66). While not engaging in an activity and ceasing to engage in it are somewhat different, this difference is glossed over by Kelp \& Simion. Moreover, this difference won't matter for my subsequent argumentation. That being said, I believe that the second engagement condition is not, strictly speaking, necessary. After all, one might simply say that there are activities that are constituted by a singleton of constitutive rules. Ipso facto, violating its only member too systematically would already count as violating too many constitutive rules of that activity too systematically.

11 It is worth noting that Maitra, Johnson, and Kelp \& Simion disagree about what is necessary to engage in a rule-constituted activity. Maitra's condition is conjunctive in so far as a rule violation is "flagrant" if it is both intentional and sufficiently marked. Johnson's condition is disjunctive in so far as the rule violation(s) mustn't be frequent or with clear intent. In contrast, Kelp's \& Simion's condition contains no such conjunction or disjunction. Moreover, Maitra and Johnson emphasise intentional rule violations, while intentionality doesn't play a role for Kelp \& Simion (cf. 2020a: 129 f.).
} 
case is presented by Kelp \& Simion. They imagine a "rather chatty" "compulsive liar" who "is strongly disposed - perhaps even hard-wired - to assert $p$ only when he believes $p$ to be false" (Kelp \& Simion, 2020a: 131). Again plausibly, this compulsive lair violates $K$ Rule, $J$ Rule, $T$ Rule, and $B$ Rule with great systematicity. Still, intuitively, he does make assertions. Hence, given KSEC, we again get the result that none of these rules can be the single constitutive rule of assertion.

Moreover, Kelp \& Simion imagine a "rather chatty" individual who "came under the spell of an evil demon, who sees to it that nearly all [of his victim's] beliefs are false" (Kelp \& Simion, 2020a: 131). Plausibly, the demon victim will also violate $K$ Rule and $T$ Rule (though not $B$ Rule and, arguably, not $J$ Rule $e^{12}$ ) with great systematicity. Still, intuitively, he does make assertions. Hence, given KSEC, we get additional reason for believing that neither $K$ Rule nor $T$ Rule can be the single constitutive rule of assertion.

If any of these versions of ECO were successful, then this would be bad news for proponents of CRAA. For this would show "that unless we have been heading down the wrong track in the debate on the identity of $\mathrm{C}$ entirely, there is reason to believe that [CRAA] is false" (Kelp \& Simion, 2020a: 134).

After thus presenting ECO, let me start my defence by observing that there is a difference between the rule violations committed by the two liars and by the demon victim on the one hand, and the rule violations committed by the subjects in cases (2)-(8) on the other hand. Regarding the liars and the demon victim, the problem primarily lies with their respective mental states. The liars don't believe what they assert, and the demon victim's beliefs are false. In contrast, the subjects' mental states don't play a role in cases (2)-(8). Rather, the problem lies with their behaviours. The way they behave signals that they don't accept the rules in question, that they don't care about them. In what follows, I will argue that this difference is crucial for evaluating and ultimately dismissing the different versions of ECO.

\section{A Different Engagement Condition}

Consider an activity that, like many philosophers take asserting to be, is constituted by a single constitutive rule - the activity of writing a closed-book exam. The rule can be put as follows: $\forall a$ ( $a$ may answer the questions given iff $a$ doesn't use reference material to do so) (Exam Rule). ${ }^{13}$ Exam Rule is constitutive of the activity of writing a closed-book exam in so far as this rule (when in force) governs the antecedently existing activity of answering a set of given questions and thereby makes it possible to perform the new activity of writing a closed-book exam. Put differently,

\footnotetext{
12 Internalists about justification will likely hold that the demon victim is justified in his beliefs, while externalists might disagree. However, notice that demon victim-cases have been presented to argue against externalist conceptions of justification (cf. e.g. Cohan \& Lehrer, 1983; Cohen, 1984; Pollock, 1984; Feldman, 1985; Foley, 1985). And several philosophers have provided versions of externalism that seek to capture the intuition that demon victims are justified in their beliefs (cf. e.g. Comesaña, 2002; Graham, 2012; Leplin, 2007, 2009).

13 I am using "question" in a loose sense here, meant to cover all kinds of exam-tasks.
} 
without Exam Rule one can answer a set of given questions, but one can't, in virtue of doing so, write a closed-book exam. ${ }^{14}$ Moreover, in so far as Exam Rule is unique to writing a closed book exam, it makes writing a closed-book exam the activity that it is and thereby differentiates it from other school-related activities with other rules; say, writing an open-book exam, which explicitly allows the use of (some) reference material.

Now imagine the following scenario:

(9) Anna and Sarah are class mates who are both present for a scheduled closedbook math exam. Prior to the exam, Anna has cleverly hidden all kinds of cheat sheets in her vicinity, on which she now relies for every single exam question. Although her teacher and her class mates suspect her of using cheat sheets, she isn't caught. Sarah, in contrast, hasn't prepared any cheat sheets. However, out of her disdain for math, she doesn't even look at the exam questions. Instead, just as she told her class mates she would, she turns over the question sheet and draws an unflattering caricature of Rudy Giuliani on the back.

Both Anna and Sarah violate Exam Rule in a way that is clearly intentional, sufficiently marked, ${ }^{15}$ and extremely systematic. Anna uses reference material (her cheat sheets) for every question. And her teacher as well as her class mates suspect her of doing so. Moreover, Sarah doesn't answer any of the exam questions, drawing a caricature instead. And, before the exam, she told her class mates that she would do so. Thus, they both violate MEC, JEC, and KSEC. That being said, intuitively, Anna nevertheless engages in the activity of writing a closed-book math exam. In contrast, intuitively, Sarah doesn't engage in the activity of writing a closed-book math exam. ${ }^{16}$

MEC, JEC, and KSEC, however, don't capture this difference in intuition. They all predict that both Anna and Sarah, in virtue of their rule violations, don't engage in the activity of writing a closed-book exam. Hence, case (9) provides a counterexample against MEC, ${ }^{17} \mathrm{JEC}$, and KSEC. But I believe that it also points to a way of moving forward.

\footnotetext{
${ }^{14}$ Thus, Exam Rule is different from a merely regulative rule - for example: One must not chew gum while answering a set of given questions. While this rule (when in force) governs the antecedently existing activity of answering questions, it doesn't make it possible to perform a new activity in virtue of answering questions (cf. fn. 2).

${ }^{15}$ It is clear from Maitra's writing that she takes it to be enough for a rule violation to be sufficiently marked that the person committing it is widely suspected of doing so. It is not necessary that she is actually caught. Regarding the case of Peter Rose (cf. §2), she writes: "Even before Rose's 2004 admission, most baseball fans thought that his earlier utterance expressed a falsehood. So, this was an intentional and highly marked failure to conform to both the truth and the knowledge norms" (Maitra, 2011: 283, emphasises added).

${ }^{16}$ In $\S 4$, I will discuss alternative interpretations of case (9) and assess their plausibility.

${ }^{17}$ A different counterexample against MEC is presented by Kelp \& Simion (2020a: 128, 2020b: 65). For further responses to Maitra, see Goldberg (2015: 22 ff.) and Reiland (2020: 153 f.).
} 
Given that both violate Exam Rule, the intuition that Anna but not Sarah engages in the activity of writing a closed-book exam suggests that it's not their rule violations per se that determine whether they engage in that activity. But what else could it be? What is the crucial difference between Anna and Sarah? I think that the crucial difference between the two is that Anna accepts Exam Rule as being in force for her (cf. fn. 1) while Sarah doesn't. Let me elaborate. Anna shows respect for Exam Rule in two ways. She actually tries to answer the questions that where given. Moreover, she pretends to follow the rule's demand not to use reference material. She has cleverly hidden her cheat sheets and does her best to emulate the behaviour of an honest exam taker. This accounts for the intuition that Anna still engages in the activity of writing a closed-book exam. Sarah, in contrast, signals that she doesn't care about Exam Rule. She doesn't even pretend to follow it in any way. Rather, she intentionally boycotts Exam Rule in so far as she refuses to engage with the exam questions and draws a caricature precisely because it is completely unrelated to these questions. This accounts for the intuition that Sarah doesn't engage in the activity of writing a closed-book math exam. ${ }^{18}$

Generalizing these observations, I propose the following alternative necessary condition on engaging in rule-constituted activities:

AEC: If an activity, $A$, is constituted by a set of constitutive rules, $R$, and if one doesn't accept one or more members of $R$ as being in force for one, then one doesn't engage in $A .^{19,20}$

AEC not only captures the intuitions provoked by case (9), it also captures the intuition that the subjects in cases (2)-(8) don't engage or cease to engage in the activities in question. Derek doesn't accept the three strikes rule as being in force for him (cf. Reiland, 2020: 154). Rather, he boycotts it, much like Sarah boycotts Exam Rule. Although he is well aware that he already had three strikes and although he knows that everyone else present (who pays sufficient attention) is aware of this as well, he still refuses to leave the batter's box (case (2)). Likewise, the soccer player doesn't accept one of the most central rules of the game-soccer is played with a soccer ball and a soccer ball only - as being in force for her. By coming onto the field waving a racquet, she signals that she just doesn't care (case (3)). And the things the eccentric friend does seem more or less completely unrelated to playing draughts, baking a

\footnotetext{
18 Thanks to an anonymous referee for suggesting this take on case (9).

19 AEC takes its inspiration from Reiland. He writes: "To perform a rule-constituted action at some time is to perform the antecedent action while enacting/accepting the constituting rule (or rules) at the time" (Reiland, 2020: 149). I talk of "activity" instead of "action" and focus on the negative case of not engaging in an activity in order to be closer to the critics of CRAA that I discuss in this paper.

${ }^{20}$ It is worth pointing out that AEC encompasses a necessary condition on engaging in rule-constituted activities that is proposed by Williamson. According to him, "some sensitivity to the difference - in both oneself and others - between conforming to the rule and breaking it presumably is a necessary condition of playing the game, speaking the language, or performing the speech act" (Williamson, 2000: 240). AEC encompasses this engagement condition because one can accept the constitutive rules of an activity only if one grasps them. This in turn requires that one is somewhat sensitive to the difference between conforming to these rules and breaking them (cf. Reiland, 2020: 150).
} 
cake, playing tennis, speaking English, or playing Ace of Spades. In fact, what he does seems downright bizarre in light of the respective activities. Again, this can be taken as a clear sign that he doesn't care about the constitutive rules of these activities, that he doesn't accept them as being in force for him (cases (4)-(8)).

What is more, AEC can also capture the intuition that David, unlike Derek, still plays baseball despite his rule violation (case (1)). After all, David accepts the three strikes rule as being in force for him. He tries to follow this rule. It's just that he makes an honest mistake, a mistake that neither the umpire nor anyone else present notices. And AEC can capture the intuition that a player who violates a constitutive rule of a game (like basketball or soccer) by committing a strategic foul still plays that game. The reason is that a player who does so nevertheless accepts the rule she violates as being in force for her. This can be seen from the fact that she accepts the penalty for her rule violation and continues the game (cf. Reiland, 2020: $150 \mathrm{f}$.).

As we have just seen, AEC has considerable explanatory power. It delivers the intuitively correct result for all the cases considered in this section. Thus, I take it to be preferrable over MEC, JEC, and KSEC. In what follows, I will argue that AEC doesn't pose a problem for CRAA. However, before I turn to that task, I will first respond to what I consider to be the most pressing objections against the argument I have given for AEC.

\section{Objections and Replies}

Since I have given a case-based argument for AEC, I will use this section to address some objections one might raise against (I) the setup and (II) the interpretation of case (9). Regarding the setup, one might object that the activity of writing a closedbook exam is not constituted by a single constitutive rule. In $\S 3$, I have already argued that Exam Rule should be understood as a constitutive rule. Nevertheless, one might still object along the following lines: Exam Rule is not the only constitutive rules of writing a closed-book exam. Or the formulation of Exam Rule actually contains more than one rule. Let's look at these objections in turn.

Objection I-a: One might argue that the activity of writing a closed-book exam has several constitutive rules. As actual closed-book exams come with a time-constraint, are written at a certain time and a certain place, and require a certain number of points to pass, one might hold something like the following to be constitutive rules as well: One must answer the exam questions in a certain amount of time. One must answer the exam questions at a certain place and time. One must achieve a certain number of points to pass the exam. This would call into question in how far case (9) can function as a counterexample against KSEC. After all, KSEC says that one can't break too many constitutive rules of an activity too systematically and still engage in that activity. But if there are several constitutive rules, then it might be possible to break one of these rules with great systematicity and still engage in that 
activity. ${ }^{21}$ This might account for the intuition that, despite her cheating, Anna still engages in the activity of writing a closed-book exam.

Reply: While I agree that the rules just mentioned typically govern the activity of writing an actual closed-book exam, I don't believe that they are constitutive rules. ${ }^{22}$ The reason is that these rules are not specific to that activity. They don't make writing a closed-book exam the unique activity that it is, and they don't differentiate writing a closed-book exam from other school-related activities with other rules. After all, these rules apply to other school-related activities, too. Open-book exams, for example, also typically come with a time-constraint, are written at a certain place and a certain time, and one must achieve a certain number of points to pass. Thus, we haven't been given a reason to believe that there are additional constitutive rules for the activity of writing a closed-book exam. ${ }^{23}$

Objection I-b: Another way to object to the setup of case (9) would be to argue that my formulation of Exam Rule actually contains more than one rule. To repeat: $\forall a$ ( $a$ may answer the questions given iff $a$ doesn't use reference material to do so). This rule might be split into (i) a rule that demands that one must answer the questions that were given and (ii) an additional rule that demands that one must not use reference material when answering these questions. But if the activity of writing a closed-book exam actually has two constitutive rules, instead of one, then it might be possible to break one of these rules with great systematicity and still engage in that activity. As Anna only violates (ii), this again might account for the intuition that, despite her cheating, she still engages in the activity of writing a closed-book exam.

Reply: Although it might be theoretically possible to split Exam Rule like this, it seems quite artificial to do so. I believe that the requirement not to use reference material is best understood not as independent constitutive rule, but as a specification contained within Exam Rule. It specifies the way in which the exam questions have to be answered. This understanding of constitutive rules is also in keeping with the way Kelp \& Simion (2020a: 130) formulate the constitutive rule of their own Ace of Spades: "[O]ne must continue to turn over cards from a standard deck until one turns over the ace of spades" (also cf. §2). Here, the requirement that a standard deck is used is built into the constitutive rule of Ace of Spades as a specification. It is not listed as an additional constitutive rule. Moreover, this way of thinking about rules is reflected in the rulebooks of various competitive sports. It is a rule of backstroke that "[u]pon the finish of the race the swimmer must touch the wall while on the back in his/her respective lane" (FINA rulebook 2017-2021: 11). In high jump

\footnotetext{
${ }^{21}$ Cf.: "[W] may want to allow for variation in what counts as violating too many members of a set of constitutive rules and what counts as violating them too systematically" (Kelp \& Simion, 2020a: 129).

22 Relatedly, Kelp \& Simion point out that "moral and practical norms [...] govern every performance of a given act with necessity. However, we take it that it would be rather implausible to say that moral and practical norms qualify as constitutive rules of say, moves in draughts, utterances in English or assertions" (Kelp \& Simion, 2020a: 136).

${ }^{23}$ I believe that the above rules are better understood as regulative rules. That is, they govern the antecedently existing activity of writing a closed-book exam, but don't make it possible to perform a new activity (cf. fn. 2, fn.14).
} 
we have the rule that "the bar shall never be raised by less than $2 \mathrm{~cm}$ in the High Jump [...] after each round of trials" (IAAF rulebook 2018-2019: 133). And in darts it is a rule that "[a]ll darts must be deliberately thrown in an over arm fashion, one at a time, by and from the Player's hand" (DRA rulebook 2019: 10). In each case, we find one rule containing one or more specifications, rather than additional rules.

Further objections might be raised not against the setup of case (9), but against its interpretation. On the one hand, one might argue that Anna doesn't actually engage in the activity of writing a closed-book exam. On the other hand, one might argue that Sarah does actually engage in the activity of writing a closed-book exam. Again, let's look at these objections in turn.

Objection II- $a$ : One might argue that Anna, in virtue of cheating, doesn't really engage in the activity of writing a closed-book exam. She only fools other into believing that she does. Kelp \& Simion suggest that we should interpret cases in which systematic cheating takes place in this way. To do so, they again look at cases (4)-(7): "If, [...], one somehow manages to be so surreptitious about [one's rule violations] that one gets others to think that one is playing draughts/baking Jamie Oliver's chocolate cake/playing tennis/speaking English, then one is simply fooling them into thinking that one is engaging in these activities even though one is not" (Kelp \& Simion, 2020a: 130, fn. 4). Given this interpretation, case (9) wouldn't provide a counterexample against MEC, JEC, KSEC and thus fail to motivate AEC.

Reply: There is reason to resist this interpretation of case (9). To see why, it is helpful to first re-examine cases (4)-(7). Remember that the eccentric friend moves his droughts pieces horizontally and vertically, rather than diagonally / mixes kiwis, kidney and marmite, rather than chocolate and butter / punches his tennis opponent, rather than hitting the ball / and utters strings of the phoneme 'ka', rather than English words. Hence, as pointed out in the last section, the things he does are more or less completely unrelated to the respective activities and even seem downright bizarre in light of them. I take these observations to be crucial for explaining the intuition that if the friend somehow manages to be surreptitious about what he does, then he would only be fooling others into believing that he engages in these activities. We can use the cake-example to make this vivid. Imagine that someone learns about the surreptitious kiwi-kidney-marmite-shenanigans. It would be natural for her to say something like: "Oh, he really tricked me. I though he was baking a chocolate cake, while in reality he did something completely different". Surely, similar reactions would be as natural with regard to the other cases presented by Kelp \& Simion. $^{24}$

Now contrast this with case (9). What Anna does isn't only directly related to the activity of writing a closed-book exam, it can best be explained in light of this activity. She uses her cheat sheets in order to answer the exam questions as well as possible. Hence, it would be strange to react to what she does by saying something like:

\footnotetext{
${ }^{24}$ Moreover, this would be a natural reaction to a variation of case (3), where the soccer player somehow manages to be surreptitious about her racquet-wielding. (I don't discuss case (1) here, because Maitra assumes that, despite his rule violation, David still plays baseball. And I don't discuss case (2) here, because it is built into the case that those present are aware of Derek's rule violation).
} 
"Oh, she really tricked me. I thought she was writing a closed-book exam, while in reality she was doing something completely different". Put differently, it would be strange to claim that she only fooled others into believing that she was engaging in the activity of writing a closed-book exam. It seems much more natural to say that she cheated while engaging in this activity. ${ }^{25}$ And given this natural interpretation of what Anna does, case (9) speaks against MEC, JEC, KSEC and in favour of AEC.

Objection II- $b$ : What about Sarah? She has showed up for the exam, sits at her allocated place for at least some of the exam time, uses the question sheet, and will presumably get an F. Based on these considerations, one might object that Sarah does actually engage in the activity of writing a closed-book exam. It's just that she does so very badly. While this objection doesn't affect case (9) in its capacity as a counterexample against MEC, JEC, KSEC, it would still (at least partly) rob AEC of its motivation.

Reply: Again, there is reason to resist this interpretation. To see why, a comparison with a sample of the cases presented in $\$ 2$ will be instructive. In each case, the subject's behaviour turns out to be relevantly similar to Sarah's behaviour. Derek has showed up for the baseball game in his capacity as a player, spends some time in the batter's box, tries to hit the ball, and will presumably get a penalty for his rule violation (case (2)). Similarly, the racquet-wielding soccer player has showed up for the game in her capacity as a player, spends some time on the soccer field, and will presumably also get a penalty for her rule violation (case (3)). And the eccentric friend has showed up for a game of droughts, sits at his allocated place at the board for some time and, during that time, moves his droughts pieces. And we might well say that he loses the game in virtue of constantly moving his pieces horizontally and vertically rather than diagonally (case (4)). Moreover, he sits down with a deck of cards to play Ace of Spades, turns over playing cards, and stops at a certain card (although the wrong one). And we might well say that he loses at Ace of Spades in virtue of stopping at the wrong card (case (8)). ${ }^{26}$ Hence, if one agrees that the subjects in these cases don't actually play baseball, soccer, droughts and Ace of Spades, respectively (and it's not just that they play these games very badly), then one should also agree that Sarah doesn't engage in the activity of writing a closed-book exam - although she has showed up for the exam, sits at her allocated place, spends some time drawing on the question sheet, and ultimately gets an $\mathrm{F}^{27}$ In a way, things seem even clearer with Sarah as compared to some of the above cases. After all, refusing

\footnotetext{
25 Similarly, Ridge (2020: 13) remarks that "we intuitively do not think that someone who cheats throughout a game has never played the game (think of someone secretly consulting the internet while playing Trivial Pursuit, say)". Moreover, the same considerations that were presented above can be used to account for this intuition. We have the intuition the player who looks up answers on the internet throughout the game cheats while playing Trivial Pursuit because what she does can best be explained in light of her playing that game. Thus, as with Anna, it seems plausible to say that she accepts the rules of Trivial Pursuit as being in force for her (cf. §3). - For further considerations to the effect that cheats engage in the activities they cheat at, see Kreider (2011).

26 I have chosen this sample because I believe that the parallels to Sarah's behaviour are especially stark here. That being said, I believe that similar considerations also apply to the other cases presented in $\S 2$.

27 Of course, one might say that in the above cases the subjects do engage in the respective activities. It's just that they do so very badly. While I don't find this very plausible, it's a coherent position to take. Still, it isn't a live option for Maitra, Johnson, and Kelp \& Simion. If they were to say that the respective
} 
to leave the batter's box in order to continue playing or moving one's pieces horizontally and vertically seem closer to playing baseball and droughts, respectively, than drawing an unflattering caricature of Rudy Giuliani seems to writing a closedbook math exam.

\section{CRAA and ECO}

AEC predicts that if one doesn't accept one or more of the constitutive rules of an activity as being in force for one, then one doesn't engage in that activity. This allows that someone who violates one or more of the constitutive rules of an activity may still engages in that activity. The reason is that one can violate one or more of the constitutive rules of an activity while nevertheless accepting these rules as being in force for one (cf. §3). Hence, given AEC, the issue with regard to CRAA boils down to the following question:

(Q): Do the liars and the demon victim (cf. §2) accept the candidate constitutive rules of assertion (cf. §1) as being in force for them?

If they don't, then this indicates that CRAA is false with regard to these candidate rules. After all, the liars and the demon victim intuitively do make assertions. If, however, the liars and the demon victim do accept the candidate constitutive rules of assertion as being in force for them, then these cases don't pose a problem for CRAA.

Let's start with the case of the demon victim, since things are especially clear here. ${ }^{28}$ Kelp \& Simion (2020a: 131) describe the demon victim as being "exceptionally sincere". Hence, it is safe to say that he asserts that $p$ only if he takes himself to know that $p$. Very plausibly, this also means that he asserts that $p$ only if he believes $p$ to be true and has some justification for this belief. ${ }^{29}$ This in turn means that he accepts $K$ Rule, and by extension, $J$ Rule, B Rule, and $T$ Rule as being in force for him. ${ }^{30}$ It's just that, unbeknownst to him and through no fault of his own, most of his beliefs are false. ${ }^{31}$

\section{Footnote 27 (continued)}

activities are performed in these cases, then they would (at least to a large extend) lose their motivation for MEC, JEC, KSEC and, ipso facto, would no longer have a substantive case against CRAA.

${ }^{28}$ Notice that the demon victim-case constitutes a somewhat weaker attack against CRAA than the two liar-cases. While the latter, if successful, would speak against K Rule, T Rule, J Rule, and B Rule, the former, if successful, would only speak against $K$ Rule and $T$ Rule (or any factive version of $C$ Rule for that matter), but not against $B$ Rule and, arguably, not against $J$ Rule (see fn. 12).

29 Relatedly, Marsili (2018: 639) remarks that "[k]nowledge is understood to entail belief, justification and truth, so that in order to follow [K Rule], you also have to follow all the other rules [ $J$ Rule, B Rule, T Rule]".

${ }^{30}$ These remarks, as well as the remarks that follow, are meant to be neutral with regard to the question which version of $C$ Rule is correct.

${ }^{31} T$ Rule and $K$ Rule have been criticised on the grounds that (a) someone who violates a rule can be appropriately criticised for doing so and that (b) it seems inappropriate to criticise someone who says something false through no fault of her own (e.g., Douven, 2006; Kneer, 2018; Lackey, 2007, 2008; Marsili, 2018). For different responses to this criticism, see, for example, DeRose, (2002); Adler (2002); Turri (2014, 2016). 
What about the liars? Unlike the demon victim, they intentionally violate all the candidate rules just listed. Still, this doesn't mean that they don't accept these rules as being in force for them. In fact, it's quite the opposite. In order to deceive her audience about $p$, a liar has to represent herself as knowing that $p$ (cf. Reiland, 2020: 148). Very plausibly, this also means that a liar has to represents herself as justifiedly believing $p$ to be true (cf. fn. 29). Moreover, if a liar's assertion gets challenged, she has to defend it. That is, she has to provide reasons that speak in favour of her assertion being true. If she fails to do so, then, very likely, her lie will fall flat. In short, a liar has to publicly accept $K$ Rule, and by extension, $J$ Rule, B Rule, and $T$ Rule as being in force for her. ${ }^{32}$ She has to somehow signal to her audience that these rules govern what she says (cf. Reiland, 2020: 150; also cf. fn. 1). If she were to fail to do so, then her lie couldn't have its intended effect.

By way of taking stock, we can answer (Q) as follows: Although, unbeknownst to him, the demon victim violates $K$ Rule and $T$ Rule, he still accepts these rules as being in force for him. And although the two liars intentionally violate $K$ Rule, $J$ Rule, $B$ Rule, and $T$ Rule, they nevertheless accept these rules as being in force for them. Hence, given AEC, $K$ Rule, $J$ Rule, B Rule, and $T$ Rule all survive as viable candidates for being the single constitutive rule of assertion.

While this result is good news for proponents of CRAA, one might still wonder if there are problem cases for this account. If AEC is on the right track, then in order to have a successful version of ECO one would have to produce a case that exhibits the following features ${ }^{33}$ :

(i) A speaker, S, doesn't accept any of the versions of $C$ Rule listed above as being in force for her. ${ }^{34}$

(ii) Intuitively, S's utterance still counts as an assertion.

Can such a case be found? I will end this section by arguing - by way of example- that there is reason to believe that the answer is "No".

Let's start by considering a phenomenon that is often differentiated from lyingbullshitting. According to Harry Frankfurt, the "essence of bullshit" is a "lack of connection to a concern with truth [...] [an] indifference to how things really are" (Frankfurt, 1988: 125, 2005: 33 f.). While a liar intentionally tries to hide the truth from her audience, a bullshitter just doesn't care whether what she says is true or not. Two things are worth noting here. Frist, plausibly, someone who bullshits may well violate $K$ Rule, J Rule, B Rule, and T Rule. Second, intuitively, someone

\footnotetext{
32 In this regard, lying is like cheating. In order to cheat successfully, one needs to publicly accept the rules of the activity one cheats at. On the close relation between lying and cheating, see, for example, Williamson (2000: 238) and Reiland (2020: 148).

33 That is, of course, absent an additional plausible necessary engagement condition that (a) also spells trouble for CRAA and (b) doesn't succumb to the same line of objection as MEC, JEC, and KSEC.

${ }^{34}$ It is necessary that $\mathrm{S}$ doesn't accept any of the different versions of $C$ Rule as being in force for her. Otherwise, we would - as with Kelp's \& Simion's demon victim-case - only have a case that gives us reason to prefer certain versions of $C$ Rule over their competitors (cf. fn. 12 and fn. 28).
} 
who bullshits nevertheless makes assertions. ${ }^{35}$ This raises the question whether a bullshitter accepts the rules she violates as being in force for her. If she doesn't, then we would have a case that satisfies (i) and (ii). ECO would rear its head again.

Fortunately for proponents of CRAA, there is good reason to believe that a bullshitter accepts these rules as being in force for her. To see why, consider an important parallel between the liar and the bullshitter. Frankfurt (1988: 130) remarks that "[b]oth he [the bullshitter] and the liar represent themselves falsely as endeavoring to communicate the truth. The success of each depends upon deceiving us about that". This in turn means that the remarks made in connection with the liar apply to her as well. In order to deceive her audience, the bullshitter has to represent herself as knowing what she asserts. Again, very plausibly, this also means that the bullshitter has to represent herself as justifiedly believing what she asserts to be true. Moreover, if the bullshitter's assertion gets challenged, she has to defend it. That is, she has to provide reasons that speak in favour of her assertion being true. If she fails to do so, then, very likely, her bullshit won't fly. In short, just like the liar, the bullshitter has to publicly accept $K$ Rule, and by extension, $J$ Rule, B Rule, and T Rule as being in force for her. She too has to somehow signal to her audience that these rules govern what she says. Otherwise, her bullshit couldn't have its intended effect.

So far, we have only encountered cases where the subjects accept the rules they violate as being in force for them. Let's now look at some cases where, plausibly, the subjects don't accept $K$ Rule, J Rule, B Rule, and T Rule as being in force for them. ${ }^{36}$ Imagine that my spouse and I go to a department store to try on some ties and that, just for fun, I put on a tie with a Teletubbies print. Smirking all over her face, my spouse says "This tie is great for a job interview". In virtue of her smirking, my spouse clearly signals that she doesn't accept K Rule, J Rule, B Rule, T Rule as being in force for her; that, right now, these rules don't govern her verbal behaviour. ${ }^{37} \mathrm{Or}$ imagine that an English learner says "A big black bear sat on a big black rug" to practise her pronunciation. Here, the context of utterance makes it clear that she doesn't accept K Rule, J Rule, B Rule, T Rule as being in force for her. She isn't even concerned with the meaning of the sentence she utters. Rather, she is just concerned with not slipping up while she utters that sentence. This raises the question whether these utterances count as assertions.

I don't think so. Obviously, my spouse hasn't made any claim to the effect that the Teletubbies tie would be great for a job interview. She was only pulling my leg. And if I, based on her words, would now form the belief that this tie would indeed be a wise sartorial choice for such an occasion, then this would just show that I am really bad at reading people. Likewise, the English learner hasn't made any claim

\footnotetext{
35 Frankfurt is explicit about taking bullshitters to make assertions when he writes: "Through excessive indulgence in the latter activity [bullshitting], which involves making assertions without paying attention to anything except what it suits one to say, a person's normal habit of attending to the ways things are may become attenuated or lost" (Frankfurt, 1988: 132; emphasis added).

36 The first case is inspired by a similar case presented by Rescorla (2009: 108), while the second case takes its inspiration from Reiland (2020: 152).

37 Note that my spouse isn't bullshitting. Unlike the bullshitter, she makes no attempt to deceive anyone about what she is up to.
} 
to the effect that a big black bear sat on a big black rug. She was only performing an exercise. And if any listener, based on her words, would now form a belief about the whereabouts of a big black bear, then this would just show that said listener completely misunderstood the purpose of the utterance. ${ }^{38}$ So, once again, we haven't found a case that satisfies (i) and (ii).

\section{Conclusion}

In this paper, I have responded to different versions of ECO in two steps. First, I have presented a counterexample against MEC, JEC, and KSEC that shows that they all lead to counterintuitive results. Based on this result, I have proposed an alternative necessary condition on engaging in rule-constituted activities, called "AEC" - if one doesn't accept one or more of the constitutive rules of an activity as being in force for one, then one doesn't engage in that activity. Second, I have argued that the demon victim and the liars do accept $K$ Rule, and by extension, $J$ Rule, B Rule, and $T$ Rule as being in force for them. Hence, given AEC, the intuition that the liars and the demon victim do make assertions doesn't pose a problem for CRAA. In addition, to give further support to CRAA, I have discussed some cases not considered by Maitra, Johnson, and Kelp \& Simion. And I have concluded that, given AEC, these cases are unproblematic for CRAA, too.

More generally, I hope to have shown that the analogy between the different versions of $C$ Rule and the constitutive rules of a given activity holds up remarkably well. If a subject violates the different versions of $C$ Rule while still accepting these rules as being in force for her, then we have the intuition that she does make an assertion. And if a subject doesn't accept these rules as being in force for her, then we have the intuition that she fails to make an assertion (cf. §5). This is just what we find with the constitutive rules of a given activity. If a subject violates the constitutive rules of an activity while still accepting these rules as being in force for her, then we have the intuition that she still engages in that activity. And if a subject doesn't accept the constitutive rules of an activity as being in force for her, then we have the intuition that she doesn't engage in that activity (cf. §3). While this result might not conclusively show that CRAA is correct, it gives us good reason to be optimistic in this regard.

Acknowledgements I would like to thank Wolfgang Freitag, Marc Andree Weber, Helge Rückert, NadjaMira Yolcu, Eva Schmidt, Alexander Dinges, Andy Mueller, Milena Bartholain, and an anonymous referee for their very helpful comments on earlier drafts of this paper. Moreover, I would like to thank Clarisse Backes, whose tales of her wild school days inspired case (9).

Funding Open Access funding enabled and organized by Projekt DEAL. The research was generously supported by the Fritz Thyssen Stiftung.

Open Access This article is licensed under a Creative Commons Attribution 4.0 International License, which permits use, sharing, adaptation, distribution and reproduction in any medium or format, as long as

$\overline{38}$ For related discussion, see Kelp \& Simion (2020a: 131). 
you give appropriate credit to the original author(s) and the source, provide a link to the Creative Commons licence, and indicate if changes were made. The images or other third party material in this article are included in the article's Creative Commons licence, unless indicated otherwise in a credit line to the material. If material is not included in the article's Creative Commons licence and your intended use is not permitted by statutory regulation or exceeds the permitted use, you will need to obtain permission directly from the copyright holder. To view a copy of this licence, visit http://creativecommons.org/licen ses/by/4.0/.

\section{References}

Adler, J. (2002). Belief's own Ethics. MIT Press.

Bach, K. (2008). Applying pragmatics to epistemology. Philosophical Issues, 18(1), 68-88.

Cohen, S. (1984). Justification and truth. Philosophical Studies, 46(3), 279-295.

Cohen, S., \& Lehrer, K. (1983). Justification, truth, and coherence. Synthese, 55(2), 191-207.

Comesaña, J. (2002). The diagonal and the demon. Philosophical Studies, 110(3), 249-266.

DeRose, K. (2002). Assertion, knowledge, and context. The Philosophical Review, 111(2), 167-203.

Cappelen, H. (2011). "Against Assertion.” J. Brown \& H. Cappelen (eds.). Assertion: New Philosophical Essays. Oxford: Oxford University Press. 21-48.

Douven, I. (2006). Assertion, knowledge, and rational credibility. The Philosophical Review, 115(4), $449-485$.

Feldman, R. (1985). Reliability and justification. The Monist, 68(2), 159-174.

Foley, R. (1985). What's Wrong with Reliabilism? The Monist, 68(2), 188-202.

Frankfurt, H. (1988). On bullshit (pp. 117-133). Cambridge University Press.

Frankfurt, H. (2005). On bullshit. Princeton University Press.

Goldberg, S. (2015). Assertion: On the philosophical significance of assertoric speech. Oxford University Press.

Graham, P. (2012). Epistemic Entitlement. Noûs, 46(3), 449-482.

Hawthorne, J. (2004). Knowledge and lotteries. Oxford University Press.

Hill, C., \& Schechter, J. (2007). Hawthorne's lottery puzzle and the nature of belief. Philosophical Issues, 17, 102-122.

Hindriks, F. (2007). The status of the knowledge account of assertion. Linguistics and Philosophy, 30(3), 393-406.

Johnson, C. (2018). What Norm of Assertion? Acta Analytica, 33(1), 51-67.

Kelp, C., \& Simion, M. (2020). The C account of assertion: A negative result. Synthese, 197(1), $125-137$.

Kelp, C. \& Simion M. (2020b). "Assertion: The Constitutive Norms View". In S. Goldberg (Ed.): The Oxford Handbook of Assertion (pp. 59-73). Oxford: Oxford University Press.

Kneer, M. (2018). The norm of assertion: Empirical data. Cognition, 177, 165-171.

Kreider, A. (2011). Game-playing without rule-following. Journal of the Philosophy of Sport, 38(1), $55-73$.

Kvanvig, J. (2011). "Norms of assertion". J. Brown \& H. Cappelen (eds.). Assertion: New philosophical essays. Oxford: Oxford University Press. 233-250.

Lackey, J. (2007). Norms of assertion. Noûs, 4(4), 594-626.

Lackey, J. (2008). Learning from words: Testimony as a source of knowledge. Oxford University Press.

Leplin, J. (2007). In defense of reliabilism. Philosophical Studies, 134(1), 31-42.

Leplin, J. (2009). A theory of epistemic justification. Springer.

Maitra, I. (2011). "Assertion, norms, and games". J. Brown \& H. Cappelen (eds.). Assertion: New philosophical essays. Oxford: Oxford University Press. 277-296.

Marsili, N. (2018). Truth and assertion: Rules vs. Aims. Analysis, 78(4), 638-648.

Pagin, P. (2016). Problems with norms of assertion. Philosophy and Phenomenological Research, 93(1), 178-207.

Pollock, J. (1984). Reliability and justified belief. Canadian Journal of Philosophy, 14(1), 103-114.

Reddiford, G. (1985). Constitutions, institutions, and games. Journal of the Philosophy of Sport, 12(1), 41-51. 
Reiland, I. (2020). Constitutive rules: Games, language, and assertion. Philosophy and Phenomenological Research, 100(1), 136-159.

Rescorla, M. (2009). Assertion and its constitutive norms. Philosophy and Phenomenological Research, $79(1), 98-130$.

Ridge, M. (2019). "How to Play Well with Others". T. Hurka (ed.). Games, Sports, and Play: Philosophical Essays. Oxford: Oxford University Press. 74-96.

Ridge, M. (2020). "Individuating games". Synthese, Online First. 1-28.

Turri, J. (2014). Knowledge and suberogatory assertion. Philosophical Studies, 167(3), 557-567.

Turri, J. (2016). Knowledge and the norm of assertion: An essay in philosophical science. Open Book Publishers.

Weiner, M. (2005). Must We Know What We Say? The Philosophical Review, 114(2), 227-251.

Whiting, D. (2013). Stick to the facts: On the norms of assertion. Erkenntnis, 78(4), 847-867.

Williamson, T. (1996). Knowing and asserting. The Philosophical Review, 105(4), 489-523.

Williamson, T. (2000). Knowledge and its limits. Oxford University Press.

Publisher's Note Springer Nature remains neutral with regard to jurisdictional claims in published maps and institutional affiliations. 